\title{
Ônus da Prova na defesa coletiva ambiental: Uma perspectiva alinhada à tutela
}

\section{efetiva do meio ambiente}

\author{
Burden of Proof in the Collective Environment Protection: A perspective to enforce environmental
} protection

Cargo de Prueba en Defensa Ambiental Colectiva: Una perspectiva alineada con la protección efectiva del medio ambiente

Recebido: 24/02/2021 | Revisado: 03/03/2021 | Aceito: 31/05/2021 | Publicado: 13/06/2021

\author{
Luana Pedrosa de Figueiredo Cruz \\ ORCID: https://orcid.org/0000-0001-6966-5260 \\ Universidade de Itaúna, Brasil \\ E-mail: luanapedrosa@uol.com.br \\ Lincoln Machado Alves de Vasconcelos \\ ORCID: https://orcid.org/0000-0001-7168-8269 \\ Universidade de Itaúna, Brasil \\ E-mail: lincolnmachadoadv@gmail.com \\ Marcus Vinicius de Abreu Sampaio \\ ORCID: https://orcid.org/0000-0002-0711-1294 \\ Pontifícia Universidade Católica de São Paulo, Brasil \\ E-mail: mas@abreusampaio.adv.br
}

\begin{abstract}
Resumo
O presente artigo tem por objetivo analisar a norma processual sob perspectiva alinhada a uma tutela coletiva efetiva dos direitos e garantias fundamentais. Discute-se a dinâmica do ônus da prova à luz dos princípios da precaução e da prevenção ambiental. Desenvolve-se argumento segundo o qual a distribuição dinâmica do ônus da prova no processo coletivo ambiental seria compatível com a efetividade da tutela jurisdicional, com vistas à promoção do direito ao meio ambiente ecologicamente equilibrado. A pesquisa é de natureza teórico-bibliográfica. Segue-se o método descritivo-analítico que instruiu a análise da legislação constitucional e a infraconstitucional, além da doutrina no tocante aos conceitos de ordem dogmática.
\end{abstract}

Palavras-chave: Distribuição e inversão do ônus da prova; Valoração; Meio ambiente; Ação coletiva.

\begin{abstract}
The purpose of this study is to analyze the procedural rule from a perspective aligned with effective protection of fundamental rights and guarantees. The dynamics of the burden of proof are discussed based in the principles of precaution and environmental prevention. An argument develops that the dynamic distribution of the burden of proof in the class actions envolving environmental suits would be compatible with the effectiveness of jurisdictional protection, with a view to promoting the right to an ecologically balanced environment. It is a theoreticalbibliographical-natured research guided by a descriptive-analytical method which had instructed the analysis of constitutional and infraconstitutional laws, as well as the doctrine informing the concepts of dogmatic order.
\end{abstract}

Keywords: Proof distribution and reversal of the burden; Valuation; Environment; Class actions.

\section{Resumen}

El propósito de este trabajo es analizar la norma procesal desde una perspectiva alineada con la protección colectiva efectiva de los derechos y garantías fundamentales. La dinámica de la carga de la prueba se discute a la luz de los principios de precaución y prevención ambiental. Se desarrolla un argumento de que la distribución dinámica de la carga de la prueba en el proceso ambiental colectivo sería compatible con la efectividad de la protección jurisdiccional, con miras a promover el derecho a un medio ambiente ecológicamente equilibrado. La investigación es de carácter teórico y bibliográfico. A esto le sigue el método descriptivo-analítico que instruyó el análisis de la legislación constitucional e infraconstitucional, además de la doctrina sobre conceptos dogmáticos.

Palabras clave: Distribución e inversión de la carga de la prueba; Valuación; Medio ambiente; Acción colectiva. 


\section{Introdução}

Alinhar a sistemática processual coletiva a uma tutela efetiva dos direitos e garantias fundamentais, apresenta-se como um dos principais desafios ao operador do direito. No contexto do presente trabalho, desenvolve-se pesquisa acerca da ressignificação do ônus da prova no processo coletivo ambiental, com a finalidade de que seja compatibilizada com as peculiaridades dos direitos e interesses em jogo.

A tarefa dos pesquisadores, da comunidade acadêmica, do Poder Público e da própria sociedade, na busca da máxima efetividade dos direitos fundamentais, notadamente em relação ao direito a um meio ambiente ecologicamente equilibrado, perpassa também pela reestruturação de alguns institutos do processo coletivo.

No tópico seguinte, estuda-se quais os signos marcantes da sistemática processual coletiva, no recorte teórico proposto.

Feito isso, no terceiro tópico, analisa-se uma perspectiva de processo coletivo voltado para a tutela efetiva do meio ambiente ecologicamente equilibrado, a partir dos princípios do interesse jurisdicional na resolução do mérito e da máxima amplitude da tutela jurisdicional coletiva.

Em tópico conclusivo, examina-se a distribuição dinâmica do ônus da prova à luz dos princípios da precaução e da prevenção, típicos da dogmática do direito ambiental.

\section{Metodologia}

A pesquisa descortina-se relevante tendo em vista a atualidade do tema relativo à defesa coletiva do meio ambiente, com vistas à preservação de direito fundamental difuso que, caso deficitariamente tutelado, comprometeria não apenas as presentes gerações, mas também as futuras.

Logo, a publicação do presente estudo em revista científica contribui para a difusão do saber. Outra não é lição de Pereira (2018), para quem: “as revistas científcas colaboram com a educação informal e, essa contribui para que a educação formal alcance sucessos maiores uma vez que podem fornecer informações e subsídios para as pessoas que estão estudando no ensino formal em alguma determinada área do saber”.

Assim, a partir da investigação de aspectos doutrinários e da análise documental (notadamente de julgados recentes no âmbito de Tribunais Superiores), discute-se uma ressignificação da distribuição do ônus da prova à luz dos princípios da precaução e da prevenção ambiental. A discussão perpassa pela investigação da distribuição dinâmica do ônus da prova no processo coletivo ambiental. É dizer, o recorte teórico compreende a problemática da compatibilização da dinâmica supramencionada com a efetividade da tutela jurisdicional, com vistas à promoção do direito ao meio ambiente ecologicamente equilibrado.

Conclui-se pela necessidade de se harmonizar a sistemática processual coletiva às especificidades do direito difuso e transgeracional a ser tutelado.

\section{Resultados e Discussão}

Antes de examinar o processo coletivo no contexto do direito ao meio ambiente ecologicamente equilibrado, cumpre fazer uma breve incursão na definição de processo coletivo.

Segundo Luiz Manoel Gomes Júnior, três são os elementos essenciais para que se possa definir o processo como coletivo:

A nosso ver, há três elementos essenciais para que uma determinada demanda possa ser classificada como uma ação coletiva: a) um sistema de legitimidade diferenciada; b) regime especial da coisa julgada; e c) a defesa de um ou mais direitos coletivos. (Curso de Processo Civil Coletivo, 2008, p.14).

No tocante ao primeiro aspecto há um desprendimento da regra segundo a qual a ninguém é dado postular em nome 
próprio direito alheio, nos termos do artigo 18 do Código de Processo Civil vigente.

Haveria, pois na sistemática processual coletiva, uma legitimação diferenciada, outorgada por lei àqueles que deduzem em juízo pretensões relativas a direitos coletivos em sentido amplo.

Em síntese, a atuação em juízo para a defesa de direitos coletivos não é representada por uma confluência entre a titularidade do direito material e a do direito processual.

Dito de outro modo: "O que vigora, no sistema coletivo, é a possibilidade de atuar em Juízo, para a defesa de uma categoria de direitos materiais que difere da individual, uma legitimidade deferida por expressa previsão legal, para a defesa dos direitos coletivos." (Gomes Júnior; Cruz. 2019)

Em relação ao segundo aspecto fundamental de qualquer ação coletiva, qual seja, um regime especial relativo à coisa julgada, consistiria na propriedade de produção de efeitos para além das partes, bem como na peculiaridade relativa ao regime de formação da coisa julgada secundum eventum probationis. O terceiro aspecto fundamental, por sua vez, seria a defesa em juízo de pretensão relativa a um ou mais direitos coletivos em sentido amplo, é dizer: de direitos difusos - tal como ocorre geralmente no que diz respeito a pretensão afeta ao meio ambiente -, coletivos em sentido estrito, ou individuais homogêneos.

No cenário da presente pesquisa, interessa de perto testificar soluções aptas a conferir uma resposta satisfatória ao inadiável compromisso da sistemática processual coletiva com a proteção ao meio ambiente.

Como é cediço, o direito ao meio ambiente ecologicamente equilibrado é imposição constitucional ${ }^{1}$ que tem por destinatário o Poder Público e a coletividade, depositários do dever de defendê-lo e preservá-lo para as presentes e futuras gerações.

Não poderia a dogmática processual quedar-se inerte, indiferente à imperiosa importância da magnitude constitucional em questão.

Cumpre, destarte, examinar doravante alguns aspectos principiológicos, ambos concatenados à efetividade da prestação jurisdicional.

Conforme salientado em tópico inicial, a proteção jurisdicional do meio ambiente pela tutela coletiva, exige uma releitura de alguns institutos tradicionais da sistemática processual, adaptando-os às peculiaridades do direito ambiental.

Sem maiores esforços, seria possível vislumbrar a possibilidade de litígios de natureza estrutural natureza na seara ambiental. Casos emblemáticos nos quais o Judiciário foi retirado de sua inércia para solucionar controvérsias como as catástrofes ambientais vivenciadas em Minas Gerais².

Um processo de caráter estrutural seria, segundo Owen Fiss: “[...] aquele no qual um juiz, enfrentando uma burocracia estatal no que tange aos valores de âmbito constitucional, incumbe-se de reestruturar a organização para eliminar a ameaça imposta a tais valores pelos arranjos institucionais existentes. Essa 'injunction' é o meio pelo qual essas diretivas de reconstrução são transmitidas." (Fiss, 2017).

Situações nas quais as pretensões deduzidas em juízo seriam enfrentadas de maneira diversa de como ocorre em um processo típico, isto é, do processo individual, bem como diferente de uma demanda coletiva 'regular'. Ou, como defendem Samuel Cota e Leonardo Nunes (2018): "os litígios estruturais são marcados pela policentria, com uma clara imbricação de interesses, todos relacionados e dependentes entre si e muitas vezes antagônicos, como a metáfora da teia de aranha utilizada por Fuller.".

${ }^{1}$ Constituição Federal, art. 225: Todos têm direito ao meio ambiente ecologicamente equilibrado, bem de uso comum do povo e essencial à sadia qualidade de vida, impondo-se ao Poder Público e à coletividade o dever de defendê-lo e preservá- lo para as presentes e futuras gerações. (BRASIL, 2015)

${ }^{2} \mathrm{Nas}$ cidades de Brumadinho e de Mariana 
Logo, se o próprio provimento jurisdicional reveste-se de especial qualidade, revelando-se como medida estruturante, tudo indica que a dinâmica de sua construção também ganha novos contornos.

Em suma, conforme leciona Almeida (2003) tem-se que:

"Admite-se para a proteção jurisdicional dos direitos coletivos todos os tipos de ação, procedimentos, medidas, provimentos etc. Todos os instrumentos processuais necessários e eficazes poderão ser utilizados na tutela jurisdicional coletiva. Cabe ação de execução em todas as espécies, ações de conhecimento com todos os tipos de provimentos - declaratório, constitutivo, condenatório ou mandamental."

Afinal, o processo não mais poderia ser concebido como compartimento absolutamente estanque, imune ao direito material que lhe clama por uma solução: as pretensões deduzidas em juízo devem ser pacificadas - leia-se: solucionadas mediante técnicas processuais ajustadas ou ajustáveis às vicissitudes do caso concreto.

Nesse diapasão, um dos exemplos mais emblemáticos de tal ajuste, ora proposto, diz respeito justamente à inversão do ônus prova no processo coletivo ambiental.

Consoante se depreende do teor do artigo $6^{\circ}$, VIII, do Código de Defesa do Consumidor, combinado com o artigo 21 da Lei da Ação Civil Pública, o microssistema processual coletivo permite uma dinâmica probatória específica, notadamente em consideração às peculiaridades das pretensões deduzidas em juízo.

Acerca da possibilidade em comento, precisa é a advertência de Miranda, M. P. S. (2010), ao sustentar, em estudo sobre o tema, que:

\begin{abstract}
"Conquanto o art. 21 da LACP não permita, prima facie, a utilização da inversão do ônus da prova prevista no art. $6^{\circ}$ do CDC, que trata dos direitos do consumidor, pois a integração das duas normas acima referidas restringir-se-ia ao tratado no Título III do CDC, que versa sobre a defesa do consumidor em juízo, dúvida não resta de que a inversão do ônus da prova é disposição processual e, portanto, integra ontológica e teleologicamente o Título III. Ademais, o CDC é diploma essencialmente principiológico, o que reforça a possibilidade da admissão do mecanismo da inversão do ônus da prova em todas as demandas difusas, aí incluídas as ambientais."
\end{abstract}

Pertinente, nessa toda, que seja rememorada a teoria do diálogo das fontes, pela qual seria possível um ganho de coerência e efetividade no ordenamento jurídico. A aludida teoria ganha especial relevo no cenário do processo coletivo.

Segundo Marques, C.L. (2004) a teoria do diálogo das fontes alavancaria a coesão do sistema:

“Aceite-se ou não as razões a pós-modernidade, a verdade é que, na sociedade complexa atual, com a descodificação, a tópica e a microrrecodificação (como a do CDC) trazendo uma forte pluralidade de leis ou fontes, a doutrina atualizada está à procura de uma harmonia ou coordenação entre estas diversas normas do ordenamento jurídico (concebido como sistema). É a denominada "coerência derivada ou restaurada" ("cohérencedérivée ou restaurée"), que procura uma eficiência não só hierárquica, mas funcional do sistema plural e complexo de nosso direito contemporâneo. Erik Jayme alerta-nos que, nos atuais tempos pós-modernos, a pluralidade, a complexidade, a distinção impositiva dos direitos humanos e do "droit à la differènc" (direito a ser diferente e ser tratado diferentemente, sem necessidade de ser "igual" aos outros) não mais permitem este tipo de clareza ou de "monossolução". A solução atual ou pós-moderna é sistemática e tópica ao mesmo tempo, pois deve ser mais fluida, mais flexível, a permitir maior mobilidade e fineza de distinções. Hoje, a superação de paradigmas foi substituída pela convivência ou coexistência dos paradigmas, como indica nosso título. Efetivamente, raramente encontramos hoje a revogação expressa, substituída pela incerteza da revogação tácita indireta, através da ideia de "incorporação", como bem expressa o art. 2.043 do novo Código Civil. Há mais convivência de leis com campos de aplicação diferentes, do que exclusão e clareza. Seus campos de aplicação, por vezes, são convergentes e, em geral diferentes, mas convivem e coexistem em um mesmo sistema jurídico que deve ser ressistematizado. O desafio é este, aplicar as fontes em diálogo de forma justa, em um sistema de direito privado plural, fluido, mutável e complexo."

Nesse giro, no contexto do presente trabalho, tem-se que objeto da lide demanda uma tutela ajustada às suas particularidades: não se poderia conceber uma sistemática processual completamente alheia / indiferente, por exemplo, aos 
princípios da precaução e da prevenção ambiental; tampouco seria razoável que se desconsiderasse a qualidade dos interesses em jogo - como ocorre no caso do direito fundamental ao meio ambiente ecologicamente equilibrado.

Conforme a lição de Godinho, R.R. (2007) negar-se uma distribuição dinâmica ou até mesmo a inversão do ônus da prova, poderia representar a negativa da própria prestação jurisdicional:

“É necessário perceber que a inversão do ônus da prova é imperativo de bom senso quando ao autor é impossível, ou muito difícil, provar o fato constitutivo, mas ao réu é viável, ou muito mais fácil, provar a sua inexistência. Não permitir, em determinadas hipóteses, a inversão do ônus da prova é o mesmo que negar a jurisdição.”

O Superior Tribunal de Justiça (Brasil, 2020) já sufragou a possibilidade da inversão do ônus da prova em função do princípio da prevenção e precaução:

PROCESSUAL CIVIL. AGRAVO INTERNO NA TUTELA PROVISÓRIA. CÓDIGO DE PROCESSO CIVIL DE 2015. APLICABILIDADE. CONSTITUCIONAL. AMBIENTAL. PROCESSUAL CIVIL. CONTRACAUTELA. TUTELA PROVISÓRIA DE URGÊNCIA. ART. 300 DO CÓDIGO DE PROCESSO CIVIL. REQUISITOS. PRESENÇA. DIREITO AO MEIO AMBIENTE ECOLOGICAMENTE EQUILIBRADO. FUMUS BONI JURIS. INTERESSE DIFUSO. PRINCÍPIOS DA PREVENÇÃO E PRECAUÇÃO. INVERSÃO DO ÔNUS PROBATÓRIO. SÚMULA N. 618/STJ. MEDIDA LIMINAR CONCEDIDA NA ORIGEM. REVISÃO. SÚMULA N. 7/STJ. PERICULUM IN MORA EM FAVOR DA PROTEÇÃO AMBIENTAL. ARGUMENTOS INSUFICIENTES PARA DESCONSTITUIR A DECISÃO ATACADA. APLICAÇÃO DE MULTA. ART. 1.021, § 4º, DO CÓDIGO DE PROCESSO CIVIL DE 2015. DESCABIMENTO. I - Consoante o decidido pelo Plenário desta Corte na sessão realizada em 09.03.2016, o regime recursal será determinado pela data da publicação do provimento jurisdicional impugnado. In casu, aplica-se o Código de Processo Civil de 2015. II - A concessão de tutela provisória de urgência é cabível no âmbito deste Tribunal Superior para atribuir efeito suspensivo ou antecipar a tutela em recursos ou ações originárias de sua competência, devendo haver a satisfação simultânea dos requisitos da verossimilhança das alegações e do perigo de lesão grave e de difícil reparação ao direito da parte, bem como para concessão de efeito suspensivo a recurso especial interposto. III - O direito fundamental ao meio ambiente ecologicamente equilibrado, insculpido no caput do art. 225 da Constituição da República, é interesse difuso, de titularidade transindividual, emergindo, nesse cenário, os princípios da precaução e da prevenção, os quais impõem a priorização de medidas que previnam danos à vulnerável biota planetária, bem como a garantia contra perigos latentes, ainda não identificados pela ciência. IV - Consoante o teor da Súmula n. 618/STJ, em homenagem ao princípio da precaução, impõe-se a inversão do ônus da prova nas ações civis ambientais, de modo a atribuir ao empreendedor a prova de que o meio ambiente permanece hígido, mesmo com o desenvolvimento de sua atividade. Na espécie, não se extrai dos autos nenhuma comprovação, pelo Agravante, de que sua atividade não causaria a degradação apontada na ação civil pública, constatando-se, na verdade, a iminente ameaça de severos danos ambientais, bem como à saúde pública de um semnúmero de pessoas, mormente pelo risco concreto de contaminação do rio Paraíba do Sul. V - Rever o entendimento da Corte de origem, pela concessão de medida liminar pleiteada pelo Parquet, demandaria necessário revolvimento de matéria fática, inviável em sede de recurso especial, à luz do óbice contido na Súmula n. 07 desta Corte, circunstância que revela a presença do fumus boni iuris necessário ao deferimento da tutela de urgência ora pleiteada. VII - Ainda à luz dos princípios da precaução e da prevenção, é forçoso concluir que, no bojo do exame de medidas de urgência em matéria ambiental, o periculum in mora milita em favor da proteção do meio ambiente, não sendo possível a adoção de outra solução, senão o imediato resguardo da pessoa humana e do meio ambiente, mormente em quadros fáticos críticos como o presente. VIII - Não apresentação de argumentos suficientes para desconstituir a decisão recorrida. IX - Em regra, descabe a imposição da multa, prevista no art. 1.021, § 4º, do Código de Processo Civil de 2015, em razão do mero improvimento do Agravo Interno em votação unânime, sendo necessária a configuração da manifesta inadmissibilidade ou improcedência do recurso a autorizar sua aplicação, o que não ocorreu no caso. V - Agravo Interno improvido. (AgInt no TP 2.476/RJ, Rel. Ministra REGINA HELENA COSTA, PRIMEIRA TURMA, julgado em 01/09/2020, DJe 02/10/2020).

Interessante sublinhar que no julgado paradigmático acima colacionado, o Tribunal da Cidadania alinhou uma perspectiva dinâmica na distribuição do ônus da prova a dois princípios do direito ambiental: o da precaução e o da prevenção.

Segundo Derani (1997), o princípio da precaução estaria concatenado, ligado à ideia de antecipar algo potencialmente lesivo:

O princípio da precaução está ligado aos conceitos de afastamento de perigo e segurança das gerações futuras, como também de sustentabilidade ambiental das atividades humanas. Este princípio é a tradução da busca da proteção da existência humana, seja pela proteção de seu ambiente como pelo asseguramento da integridade da vida humana. A 
partir desta premissa, deve-se também considerar não só o risco eminente de uma determinada atividade, como também os riscos futuros decorrentes de empreendimentos humanos, os quais nossa compreensão e o atual estágio de desenvolvimento da ciência jamais conseguem captar em toda densidade."

Na mesma linha, em decisão proferida em agosto do presente ano pela primeira turma do Superior Tribunal de Justiça ${ }^{3}$ :

PROCESSUAL CIVIL E AMBIENTAL. AGRAVO INTERNO NO AGRAVO EM RECURSO ESPECIAL. AÇÃO CIVIL PÚBLICA. INVERSÃO DO ÔNUS DA PROVA. PRINCÍPIO DA PRECAUÇÃO. CABIMENTO. SÚMULA 618/STJ. AFERIÇÃO DAS PECULIARIDADES DO CASO CONCRETO, AUTORIZADORAS DA INVERSÃO. REEXAME DO CONJUNTO FÁTICO-PROBATÓRIO. INVIABILIDADE. AGRAVO INTERNO DA SOCIEDADE EMPRESÁRIA A QUE SE NEGA PROVIMENTO. 1. O presente Recurso atrai a incidência do Enunciado Administrativo 3 do STJ, segundo o qual, aos recursos interpostos com fundamento no Código Fux (relativos a decisões publicadas a partir de 18 de março de 2016), serão exigidos os requisitos de admissibilidade recursal na forma do novo Código. 2. Esta Corte Superior admite a inversão do ônus da prova em ações que versem sobre degradação ambiental, nos termos da Súmula 618/STJ, cabendo às instâncias ordinárias a análise quanto aos requisitos da redistribuição dos encargos probatórios. 3. Assim, tendo o Tribunal de origem concluído pela necessidade de inversão do sobredito ônus, é inviável a alteração de suas conclusões nesta instância especial, por demandar o reexame do conjunto fático-probatório. Julgados: AgInt no AREsp. 1.373.360/PR, Rel. Min. GURGEL DE FARIA, DJe 17.10.2019; AgInt no AREsp. 620.488/PR, Rel. Min. OG FERNANDES, DJe 11.9.2018; AgInt no AREsp. 779.250/SP, Rel. Min. HERMAN BENJAMIN, DJe 19.12.2016. 4. Agravo Interno da Sociedade Empresária a que se nega provimento. (AgInt no AREsp 1580615/PR, Rel. Ministro NAPOLEÃO NUNES MAIA FILHO, PRIMEIRA TURMA, julgado em 24/08/2020, DJe 31/08/2020).

Extrai-se do teor do acórdão retromencionado que o princípio da precaução e a dinâmica do ônus probatório estariam imbricados.

Isto é diante de uma atividade potencialmente lesiva ao meio ambiente, descortina-se possível a inversão do ônus da prova: redistribuindo-se o encargo probatório de acordo com o objeto da demanda. Permita-se a transcrição do escorço de Mirra (2020):

O princípio da precaução consagra o critério da probabilidade na tomada de decisões que envolvam a questão ambiental, em detrimento do critério da certeza. Ou seja, enquanto que ao demandado incumbe o dever de demonstrar, efetivamente, que a atividade desenvolvida não é lesiva ao meio ambiente, exigindo-se, portanto, certeza absoluta da inofensividade de sua prática, ao demandante cabe demonstrar que há probabilidade da ocorrência do dano.

O mesmo raciocínio é válido no tocante ao princípio da prevenção, que, segundo Medeiros, L.P. (2013): “apoia-se na certeza científica do impacto ambiental de determinada atividade. Ele determina justamente que, com base no que a Ciência afirma ser lesivo, se pratiquem todas as medidas hábeis a prevenir a ocorrência do dano ambiental.”

Pelo exposto, não mais seria concebível uma distribuição rígida e a priori dos encargos probatórios, sem levar em consideração as vicissitudes das pretensões deduzidas em juízo.

Segundo Cremasco (2009):

A carga dinâmica, por sua vez, não sofre limitações decorrentes de previsão legislativa e tem uma aplicação mais geral, voltada para todo e qualquer tipo de processo no qual o regramento estático se mostre insuficiente ou inadequado e desde que um dos litigantes tenha maior facilidade ou esteja em melhores condições de produzir a prova respectiva.

\footnotetext{
${ }^{3}$ No mesmo sentido: PROCESSUAL CIVIL E ADMINISTRATIVO. AGRAVO INTERNO NO RECURSO ESPECIAL. OCORRENCIA DE DERRAMAMENTO DE ÓLEO. FATO INCONTROVERSO. NECESSIDADE DE RETORNO DOS AUTOS À CORTE DE ORIGEM A FIM DE QUE SE OBSERVE A EXISTÊNCIA, OU NÃO, DO NEXO CAUSAL E DO DANO AO MEIO AMBIENTE. AGRAVO INTERNO PARCIALMENTE PROVIDO PARA DAR PARCIAL PROVIMENTO AO RECURSO ESPECIAL, COM AS DEVIDAS VÊNIAS AO RELATOR. "É necessário, portanto, novo julgamento do caso a fim de que se apure o eventual prejuízo à Baia da Guanabara, pois é cediço que a Lei n. 6.938/1981 adotou a sistemática da responsabilização objetiva do agente que venha causar dano ao meio ambiente, sendo possível a inversão do ônus probatório, em sintonia com o princípio da precaução". (AgInt no REsp 1683575/RJ, Rel. Ministro NAPOLEÃO NUNES MAIA FILHO, Rel. p/ Acórdão Ministro Benedito Gonçalves, Primeira Turma, julgado em 05/03/2020, DJe 23/03/2020).
} 
Ao se deparar com demanda ambiental que conclame uma especial atenção em virtude da necessidade de se permitir uma tutela efetiva do meio ambiente ecologicamente equilibrado, carece a sistemática processual de uma ressignificação de seus institutos, máxime no tocante à dinâmica do ônus da prova.

Assim, interessa de perto o afastamento de concepções insensíveis à particularidade do objeto da demanda:

Segundo a Teoria Dinâmica de Distribuição do Ônus da Prova, ficam afastadas as regras rígidas e estáticas da distribuição do onus probandi, que passam a ser mais flexíveis, adaptáveis a cada caso concreto.

Segundo Azevedo, A.D.M. (2007), pouco importa a posição da parte, se autora ou ré; também não interessa a espécie do fato, se constitutivo, impeditivo, modificativo, ou extintivo de direitos, pois o importante é que o juiz valore, caso a caso, qual das partes dispõe das melhores condições de suportar o ônus da prova, e imponha o encargo de provar os fatos àquela que possa produzir a prova com menos inconvenientes, despesas, delongas etc., mesmo que os fatos objetos de prova tenham sido alegados pela parte contrária.

Assim, por força da incidência dos princípios da precaução e da prevenção, razoável que se transfira ao suposto degradador ambiental o ônus argumentativo de provar que sua atividade não é causadora de anos ao meio ambiente.

Conforme defendido por Brasil, D.R. (2017), citando Rodrigues (2015) e Cambi (2015), tem-se que a técnica da dinamização do ônus da prova revela-se oportuna:

Devido ao caráter subsidiário e excepcional, a técnica da dinamização do ônus da prova somente deverá ser aplicada judicialmente quando o juiz perceber eventual possibilidade de desfecho injusto para o processo, decorrente da necessidade de tomada de decisão exclusivamente com base nas regras ordinárias de distribuição dos encargos probatórios, para que se torne uma técnica processual capaz de promover a isonomia entre as partes e, assim, efetivar decisões justas, isto é, que assegurem a tutela judicial do direito material violado.

Por todo o exposto, possível verificar que o provimento jurisdicional alinhado à busca pela justiça social e harmônica com a defesa do meio ambiente ecologicamente equilibrado, depende da ressignificação de institutos tradicionais do processo, bem como de sua releitura à luz dos princípios específicos do direito ambiental.

\section{Conclusão}

A partir da aplicação da teoria do diálogo das fontes, verifica-se uma tutela processual coletiva ajustada à necessária proteção ambiental: com efeito, uma sistemática processual dissociada dos princípios da precaução e da prevenção ambiental seria incipiente para a efetivação do direito fundamental ao meio ambiente ecologicamente equilibrado.

Além disso, tampouco seria razoável - repise-se - que se concebesse uma procedimentalidade indiferente à qualidade das pretensões deduzidas em juízo por ocasião de suposta degradação ambiental.

Por fim, os poderes instrutórios do magistrado podem ser compatibilizados com a inversão do ônus probatório, notadamente em quando necessária tal medida para viabilizar a própria efetividade da prestação jurisdicional.

\section{Referências}

Almeida, G. (2003). Assagra de. Direito processual coletivo brasileiro: um novo ramo do direito processual. Saraiva.

Azevedo, A. D. M. (2007). A teoria dinâmica de distribuição do ônus da prova no direito processual civil brasileiro. Revista de Direito Ambiental, Teresina, $11(1.500)$

Miranda, M. P. S. A prova no processo coletivo ambiental. Necessidade de superação de velhos paradigmas para a efetiva tutela do meio ambiente. Eládio Lecey; Sílvia Capelli. (Org.). Revista de Direito Ambiental. 1. ed. São Paulo: Revista dos Tribunais, 2010, v. 57, p. $102-123$.

Brasil, D.R. A ressignificação do ônus probatório na defesa coletiva do meio ambiente: aspectos processuais nas ações coletivas. Revista Internacional de Direito Consinter - Derecho ante los desafios de la globalización. Ano III, n. IV. Juruá, 2017. https://revistaconsinter.com/wp-content/uploads/2017/06/ano-iiinumero-iv-a-ressignificacao-do-onus-probatorio-na-defesa-coletiva-do-meio-ambiente.pdf. 
Research, Society and Development, v. 10, n. 7, e4810713257, 2021

(CC BY 4.0) | ISSN 2525-3409 | DOI: http://dx.doi.org/10.33448/rsd-v10i7.13257

Brasil. Superior Tribunal de Justiça. Agravo Interno no TP. 2.476/RJ, Rel. Ministra Regina Helena Costa, Primeira Turma, julgado em 01/09/2020, DJe 02/10/2020. Disponível: https://scon.stj.jus.br/SCON/pesquisar.jsp. Acesso:14 out. 2020

Brasil, Superior Tribunal de Justiça. Agravo Interno no Agravo em Recurso Especial 1580615/PR, Rel. Ministro Napoleão nunes maia filho, primeira turma, julgado em 24/08/2020, DJe 31/08/2020. https://scon.stj.jus.br/SCON/pesquisar.jsp.

Cota, S. P. \& Nunes, L. S. Medidas estruturais no ordenamento jurídico brasileiro: os problemas da rigidez do pedido na judicialização dos conflitos de interesse público. Revista de Informação Legislativa, Brasília, a. 55, n. 217, p. 243-255, jan./mar. 2018.

Cremasco, S. S. A distribuição dinâmica do ônus da prova. Rio de Janeiro: GZ, 2009.

Derani, C. Direito ambiental econômico. São Paulo: Max Limonad, 1997.

Fiss, O. As formas de Justiça. In: Costa, S. H. \& Watanabe, K \& Grinover, A.P. (Org.). O processo para solução de conflitos de interesse público. Salvador: JusPODIVM, 2017. p. 119-173.

Godinho, R. R. A distribuição do ônus da prova na perspectiva dos direitos fundamentais. In: Camargo, M. N. (Org.). Leituras complementares de direito constitucional: direitos fundamentais. 2. ed. Salvador: Jus Podivm, 2007.

Gomes Júnior, L. M \& Cruz, L. P. F. Ações coletivas passivas: um diálogo com a doutrina - Primeira Parte. São Paulo, RePro, vol. 287, p. 291 - 305, Jan. 2019.

Gomes Júnior, L. M. Curso de Direito Processual Civil Coletivo. 2. ed. São Paulo: SRS, 2008, p. 14.

Marques, C. L. Superação das antinomias pelo Diálogo das Fontes: O modelo brasileiro de coexistência entre o Código de Defesa do Consumidor e o Código Civil de 2002. Revista da Escola Superior da Magistratura de Sergipe (ESMESE), nº 7, 2004, p. 29.

Medeiros, L.P. O Princípio da Prevenção Sob o Enfoque Ambiental e da Saúde: um Imperativo Sócio-democrático. Revista Direito Público. Porto Alegre: Síntese; Brasília: Instituto Brasiliense de Direito Público. Ano IX, n. 51, Maio-Jun 2013, p.51-65.

Miranda, M. P. S. A prova no processo coletivo ambiental. Necessidade de superação de velhos paradigmas para a efetiva tutela do meio ambiente. In: Eládio Lecey; Sílvia Capelli. (Org.). Revista de Direito Ambiental. 1. ed. São Paulo: Revista dos Tribunais, 2010, v. 57, p. 102-123.

Mirra, Álvaro. In: Leite, J. R. (Org.). Inovações em Direito Ambiental. Florianópolis: Fundação Boiteux, 2000. 